\title{
Tráfico de Pessoas: \\ Uma Análise da Lei N. 13.344/2016 à Luz dos Direitos Humanos
}

\section{Ronaldo Alves Marinho da Silva}

Doutor em Direito pela Universidade Presbiteriana Mackenzie (UPM). Mestre em Direito pela Pontifícia Universidade Católica do Paraná (PUC/PR). Especialista em Direitos Humanos pela Universidade do Estado da Bahia e especialista em Gestão em Segurança Pública pela Universidade Federal de Sergipe. Coordenador do Projeto de Extensão Reformatório Penal/Unit. Vice-líder do Grupo de Pesquisa Execução Penal e membro do Grupo de Pesquisa Direito Penal Econômico e Justiça Penal Internacional - Diretório de Pesquisa do CNPq. Membro do Conselho Penitenciário do Estado de Sergipe. Associado pleno do Fórum Brasileiro de Segurança Pública (FBSP). Professor-adjunto da Universidade Tiradentes. Delegado de Polícia Civil do Estado de Sergipe. Tem experiência na área de Direito, com ênfase em Direito Penal, Direito Penal Internacional, Execução Penal, Direito Penal Ambiental e Direitos Humanos. http:// lattes.cnpq.br/2969015202546827. http://orcid.org/0000-0002-6878-0280.ronaldomarinho.se@gmail.com

\section{Fernanda Caroline Alves de Mattos}

Mestranda em Ciência Jurídica pela Universidade Estadual do Norte do Paraná - Uenp. Graduada em Direito pela Universidade Tiradentes (Unit/SE). Participante do Grupo de pesquisa Intervenção do Estado na vida das pessoas do diretório CNPq. Atua em pesquisas relacionadas a Direitos Humanos, Direito Penal, Filosofia Jurídica, Sociologia Jurídica e Direito Constitucional, com ênfase na relação entre Gênero e Direito. http://lattes.cnpq.br/3266505536822300. https://orcid.org/0000-0002-5322-4126. mattos.fernandac@gmail.com

A presente produção busca tratar do tema tráfico de pessoas sob a nova ótica da Lei N. 13.344 de 2016, especialmente sob suas novas formas de proteção e prevenção do crime, com o objetivo de compreender de que modo esse novo regulamento retrata disposições de cunho internacional e constitucional na medida de coibir violações a direitos humanos, em especial a dignidade humana. Tratando, então, das previsões de direitos humanos contra tráfico de pessoas, assim como as novas diretrizes, princípios e estruturação da norma, bem como com a devida discussão crítica de direitos humanos fundamentais que se encaixa nela, o objetivo é verificar se a nova norma brasileira possui instrumentos que atendam aos preceitos internacionais e cumpram o papel protetivo adequadamente. Para isso, foi utilizada a metodologia baseada numa análise bibliográfica de método dedutivo, sob o arcabouço bibliográfico de teóricos dos direitos humanos além da análise da lei em si para atingir o cerne do problema apresentado.

Palavras-chave: Direitos humanos. Tráfico de pessoas. Lei n. 13.344/2016.

HUMAN TRAFFICKING: AN ANALYSIS OF LAW N. 13.344/2016 IN THE LIGHT OF HUMAN RIGHTS

This production seeks to address the issue of human trafficking from the new perspective of Law n. 13.344 of 2016, especially under its new forms of protection and crime prevention, with the aim of understanding how this new regulation portrays provisions of an international and constitutional nature in order to curb violations of human rights, especially human dignity. By dealing, then, with human rights provisions against human trafficking, as well as the new guidelines, principles and structuring of the norm, as well as with the due critical discussion of fundamental human rights that fit into it, the objective is to verify that the new Brazilian norm has instruments that meet international precepts and fulfill the protective role appropriately. For this, the methodology based on a bibliographic analysis of deductive method was used, under the bibliographic framework of human rights theorists besides the analysis of the law itself to reach the core of the problem presented.

Keywords: Human rights. Human trafficking. Law n. 13.344/2016.

\section{SUMÁRIO}

1 Introdução. 2 Direitos Humanos e Tráfico de Pessoas no Brasil. 3 A Nova Lei e suas Perspectivas no Âmbito do Enfrentamento ao Crime de Tráfico de Pessoas. 4 Análise Crítica Sobre a Proteção dos Direitos Humanos Fundamentais e a Lei N. 13.344/16. 5 Considerações Finais. 6 Referências. 


\section{INTRODUÇÃO}

O presente trabalho tem o escopo de analisar a Lei $\mathrm{n} 013.344 / 2016$ enquanto instrumento jurídico apto a proteger as vítimas de tráfico de pessoas e responsabilizar seus autores. Tal análise se faz importante diante da complexidade do crime em comento e a necessidade de um cuidado contínuo com relação às suas vítimas, seja no âmbito de prevenir, reprimir o crime ou acolher a pessoa à qual lhe foi retirada a liberdade e a dignidade humana.

O tráfico de pessoas é um crime vil que violenta e transforma o ser humano em mercadoria para adquirir lucro, destrói sua dignidade e o desenraiza do seio social. É um crime construído de forma complexa, com faces de incisão distintas e que não deve, de forma alguma, ser aceito, uma vez que possui origem na crise entre o Estado e própria sociedade, inspirando a existência de diversas discriminações e violência (LEAL, 2002, p. 31).

Desta forma, trazer e discutir a temática sobre a posição do ordenamento jurídico na empreitada de combate a esse tipo penal é medida que se impõe, uma vez que não somente se concretiza como violação ao bem jurídico liberdade do indivíduo, mas também é uma patente violação aos seus direitos humanos e fundamentais constitucionalmente resguardados.

A análise perfaz-se mais ainda necessária quando se observa que, de acordo com o United Nations Office of Drugs and Crimes (UNODC, 2016), o tráfico de pessoas é o terceiro crime com maior lucro mundial, perdendo apenas para os tráficos de arma e de drogas. Uma clara demonstração em que, muito mais que a subjugação social, a pessoa traficada torna-se "coisa", mercadoria. Rechaça-se sua humanidade em razão de lucro e violência, sendo importante, portanto, por meio do presente trabalho, desenvolver um olhar crítico sobre a inovação legislativa nessa seara a fim de observar se há ou não um acolhimento estatal abstrato na intenção de promover a efetiva proteção dos direitos das vítimas.

Neste trabalho o escopo principal desenvolve-se pela necessidade de se analisar criticamente a Lei N. 13.344/2016 sob o olhar dos direitos humanos internacionais e fundamentais previstos na Constituição Federal, uma vez que é uma inovação legislativa de alto impacto na proteção das vítimas e resolução dos crimes.

A escalada da presente ideia iniciará com a verificação do desenvolvimento histórico na proteção dos direitos das vítimas de tráfico humano em sede internacional e nacional, buscando ressaltar sua evolução cronometodológica e apontar, com isso, o caminho percorrido até a supracitada norma.

Após isso, objetiva-se descrever o que há na nova legislação a respeito das diretrizes que se coadunam com o Protocolo de Palermo, compreendendo em que sentido garantem a prevenção, repressão e punição para fins de enfrentamento ao tráfico de pessoas, e observando, para tanto, os dispostos nos capítulos II, III e IV em comparativo direto aos dispostos no protocolo e no Plano Nacional de Enfrentamento ao Tráfico de Pessoas que está em vigor.

Em seguida, intenta-se sintetizar criticamente a importância da proteção dos direitos humanos das vítimas conforme o ideal trazido na própria Constituição Federal de 1988. Para isso, expõe-se a visão da necessidade de proteção de direitos humanos e seu alcance nos direitos humanos das vítimas de tráfico, para compreender em que ponto a nova lei os atinge. 


\section{Humanos e}

Democracia

Para a referida produção foi empregada a metodologia por meio do uso do método dedutivo (método de abordagem) a partir de revisão bibliográfica. Utiliza-se tal método para alcançar a resposta de um problema que se faz mediante uma observação das expectativas sob teorias, que, nos ensinamentos de Popper (2004, p. 15), é o que de fato molda um trabaIho científico.

\section{DIREITOS HUMANOS E TRÁFICO DE PESSOAS NO BRASIL}

O crime de tráfico de pessoas, hoje capitulado no artigo 149-A do Código Penal Brasileiro, ${ }^{1}$ sofreu, no decurso do tempo, diversas alterações na sua interpretação e aplicação legislativa (nacional e internacionalmente) até o advento da nova lei que está sendo analisada neste trabalho. Tal evolução concretiza-se a partir das discussões internacionais sobre as formas cada vez mais eficazes para a proteção das vítimas e a punição dos traficantes.

O tema tráfico de pessoas não é um fato novo, tendo ocorrido em toda história da humanidade, mas foi com o advento da colonização que teve um tratamento comercial, ampliando sua ação e multiplicando suas vítimas com a escravidão negra para as colônias. De acordo com Ela Wiecko Volkmer de Castilho (2008), a primeira regulamentação internacional do tema surgiu com a proibição do tráfico na Convenção de Viena em 1814, o que não estancou o problema. Em seguida tivemos a edição de outros instrumentos internacionais sobre o tema: a) 1910 - Convenção Internacional para a Repressão do Tráfico de Mulheres Brancas; b) 1921 - Convenção Internacional para a Repressão do Tráfico de Mulheres e Crianças); c) 1933 - Convenção Internacional para a Repressão do Tráfico de Mulheres Maiores; d) 1947 - Protocolo de Emenda à Convenção Internacional para a Repressão do Tráfico de Mulheres e Crianças e à Convenção Internacional para a Repressão do Tráfico de Mulheres Maiores (1947); e) 1949 - Convenção e Protocolo Final para a Repressão do Tráfico de Pessoas e do Lenocínio.

Atualmente, o tema é tratado por intermédio do Protocolo Relativo à Prevenção, Repressão e Punição do Tráfico de Pessoas, em Especial Mulheres e Crianças, conhecido como Protocolo de Palermo, de 9 de novembro de 1998, sendo ele o primeiro instrumento a delimitar consensualmente o que é tráfico de pessoas e o que se deve fazer a respeito disso.

O protocolo foi desenvolvido para que pudesse não somente delimitar a conduta de traficar pessoas, mas também diferenciá-la da conduta de migração ilegal (ou contrabando de imigrantes ou também imigração irregular), a qual possui seu próprio Protocolo Internacional com suas exposições específicas. ${ }^{2}$ Tal separação percebe-se claramente quando em relação ao tráfico o termo em inglês para se tratar do tema é trafficking e para a migração é smuggling. Nesse sentido, o protocolo defende, em seu artigo terceiro, que tráfico de pessoas é:

\footnotetext{
Art. 149-A. Agenciar, aliciar, recrutar, transportar, transferir, comprar, alojar ou acolher pessoa, mediante grave ameaça, violência, coação, fraude ou abuso, com a finalidade de: I - remover-lhe órgãos, tecidos ou partes do corpo; II - submetê-la a trabalho em condições análogas à de escravo; III - submetê-la a qualquer tipo de servidão; IV - adoção ilegal; ou V exploração sexual. Pena - reclusão, de 4 (quatro) a 8 (oito) anos, e multa.

2 Protocolo Contra o Contrabando de Imigrantes por Terra, Mar e Ar, o qual complementa a Convenção das Nações Unidade Contra a Delinquência Organizada Transnacional de 2000.
} 
[...] o recrutamento, o transporte, a transferência, o alojamento ou o acolhimento de pessoas, recorrendo à ameaça ou uso da força ou a outras formas de coação, ao rapto, à fraude, ao engano, ao abuso de autoridade ou à situação de vulnerabilidade ou à entrega ou aceitação de pagamentos ou benefícios para obter o consentimento de uma pessoa que tenha autoridade sobre outra para fins de exploração. A exploração incluirá, no mínimo, a exploração da prostituição de outrem ou outras formas de exploração sexual, o trabalho ou serviços forçados, escravatura ou práticas similares à escravatura, à servidão ou à remoção de órgãos.

Dessa forma, havendo essa especificidade, no que ensina Waldimery Corrêa da Silva (2013, p. 424), o protocolo não se dispõe somente como um mero acordo entre Estados-membros; ele facilita na definição de uma maior defesa e alcance no que concerne aos direitos humanos passíveis de violação nessas circunstâncias.

Não obstante a previsão do protocolo, internacionalmente ainda se pode contar com a proteção estabelecida para migrações com fito de tráfico dentro de diversas Convenções e Tratados, a exemplo da Convenção de Viena de 1993, que, em seu artigo 18, esclarece que todo tipo de violência, contra qualquer pessoa por qualquer que seja sua etnia, gênero ou cultura, que seja um resultado até mesmo dentro do tráfico de pessoas, deve ser expurgada. Para isso, induz a necessidade de previsões legislativas e ações, nacionais e internacionais, voltadas a garantir o pleno desenvolvimento humano para evitar tais violações e proteger a dignidade humana.

Tal induzimento demanda a necessidade de olhar para o âmbito interno jurídico brasileiro. O Brasil, dentro da temática, sofreu, com o passar do tempo, certa evolução entre conceitos, definições e ações práticas para fins de atingir os objetivos gerais do Protocolo de Palermo. Afinal, como produção humana, as definições jurídicas e legislações criadas estão fadadas a possuírem erros e autorrenovarem-se à medida que a humanidade evolui.

Conforme introduziram Anamaria Marcon Venson e Joana Maria Pedro (2013, p. 68-69) em seu trabalho, em um primeiro momento nossa definição de "tráfico" desenvolveu-se dentro de um senso proibitivo da prostituição, frise-se, feminina, por meio do artigo $231^{3}$ do Código Penal de 1940, previsto no capítulo antes conhecido como "Dos Crimes contra os Costumes".

Após alguns anos, a segunda evolução, se se pode ser assim chamada, ocorreu após anos de debate feministas na intenção de desvincular o combate ao tráfico como único exclusivamente relacionado à atividade sexual remunerada exercida por mulheres.

Observa-se que o protocolo de Palermo renovou a definição em 2000 e o Brasil, em 2004, o ratificou por meio do Decreto n. 5.017, alterando-se o crime de "tráfico internacional de mulheres" para "tráfico internacional de pessoas". Apesar, contudo, de resoluta a questão de gênero - aparentemente - o legislador entendeu manter a fixação do tipo penal à questão da prostituição, ${ }^{4}$ como demonstrado na alteração feita pela Lei n. 12.015/2009, que, como explicam Venson e Pedro (2013, p. 77):

\footnotetext{
Art. 231. Promover ou facilitar a entrada, no território nacional, de mulher que nêle venha a exercer a prostituição, ou a saída de mulher que vá exercê-la no estrangeiro: Pena - reclusão, de três a oito anos.

4 O tipo penal passou a ser definido em seu caput da seguinte forma: "Promover ou facilitar a entrada, no território nacional, de alguém que nele venha a exercer a prostituição ou outra forma de exploração sexual, ou a saída de alguém que vá exercê-la no estrangeiro", vinculando o crime estritamente à exploração sexual e garantindo a proibição velada à prática exercida pela prostituta.
} 
[...] passou a tratar de tráfico de pessoa para "prostituição ou outra forma de exploração sexual", igualando prostituição à exploração, talvez buscando adequar-se um tanto mais à redação do Protocolo, que fala em "exploração da prostituição de outrem ou outras formas de exploração sexual".

Entende-se de tal posicionamento que a prostituição representa uma situação suscetível a novas violências, entre elas o tráfico, e é camuflada, pois permanece em sua inteireza numa clandestinidade social (PASTANA, 2013, p. 105). Por outro lado, quando associada ao tráfico, reduz-se o rigor da análise criminal do fato, em razão da ferida moral causada pela atividade sexual, o que dificulta o aceite social de que uma prostituta pode ser vítima de tráfico (SANTOS et al., 2008, p. 273), decorrendo, daí, um paradoxo entre o que se protege e o que se proíbe.

Voltando à evolução cronológica brasileira, em 2006, saindo da esfera das leis, o Estado brasileiro posicionou-se na criação do primeiro Plano Nacional de Enfrentamento ao Tráfico de Pessoas (PNETP), sendo atualizado para II PNETP no ano de 2013, pelo Decreto n. 7.901, o qual trouxe mais detalhamento a respeito do pilar da prevenção, proteção e punição, aplicado ao crime de tráfico de pessoas. ${ }^{5}$ Atualmente, o Brasil está preparando-se para lançar um terceiro plano e renovar as estruturas deixadas pelos dois anteriores.

Os dois planos, e em especial o segundo, vieram com o fito de fazer valer a intenção estatal de não somente punir o crime, mas abarcar a sua prevenção e o cuidado com as vítimas, antes e, mais ainda, depois de uma violação a sua liberdade e também identidade, posto que a realidade de ser vítima nesse crime é um resultado de seu desenraizamento social ao ser transformada em objeto para obtenção de lucro.

Como exemplo da importância dos Planos encontra-se uma de suas metas, dentro da Linha operativa 2, que consiste em:

Atividade 2. G - Ampliar o acesso a direitos por parte de vítimas e grupos vulneráveis ao tráfico de pessoas e a oferta de serviços e iniciativas públicas, prioritariamente em municípios e comunidades identificadas como focos de aliciamento de vítimas de tráfico de pessoas, com vistas a diminuir tal vulnerabilidade e seus impactos.

A desenvoltura dos planos, principalmente considerando a estrita forma aplicada anteriormente no Código Penal, permitia maior proteção e atuação do Estado nas esferas do crime, com campanhas e capacitação de profissionais, além da produção, gestão e disseminação de informação aos cidadãos.

Posteriormente, a segurança jurídica sobre o tema ganhou novos ares quando, em 2016, foi sancionada a Lei n. 13.344, a qual passou a tratar explicitamente sobre o tráfico de pessoas no Brasil e foi construída em moldes equivalentes ao entendimento internacional. Tal morosidade, entre ratificação do Protocolo e produção legislativa dentro de seus moldes, demonstrou um descaso com o tema por parte do Estado, o que ratifica o quanto a situação de tráfico é delicada para se afrontar, principalmente por este crime ser um evidente meio de violação da dignidade da pessoa humana, representando uma moléstia aos direitos fundamentais das vítimas. ${ }^{6}$

\footnotetext{
Comumente reconhecido como Triplo "P" do Protocolo de Palermo (Prevenção, Punição, Proteção).

6 A dignidade da pessoa humana é protegida positivamente no ordenamento jurídico por meio dos direitos fundamentais, guardando uma relação jusnaturalista direta com os direitos humanos, conforme explicita Ingo Wolfgang Sarlet, em sua obra "A eficácia dos direitos fundamentais: uma teoria dos direitos fundamentais na perspectiva constitucional” (2011, p. 32).
} 
Cinge-se, por fim, que, apesar da demora, a nova norma finalmente trouxe o que Cunha e Pinto $(2016$, p. 21) afirmam ser "a proteção do ser humano, figura central e principal objeto de preocupação do legislador", na medida em que o tipo e suas diretrizes finalmente se relacionam diretamente ao almejado internacionalmente na proteção, prevenção e punição ao crime de tráfico de pessoas.

\section{A NOVA LEI E SUAS PERSPECTIVAS NO ÂMBITO DO ENFRENTAMENTO AO CRIME DE TRÁFICO DE PESSOAS}

A Lei n. 13.344 de 2016 é muito além de apenas uma inovação legislativa; ela traz quebra de paradigmas e novos olhares sobre um tema sensível e colocado à revelia em razão de sua facilidade de ser "abafado". Ela apresenta uma construção interna voltada ao sucesso dos objetivos fundamentais internacionais relacionados ao tráfico de pessoas, já citados neste trabalho.

Sua estruturação é iniciada por meio dos seus princípios norteadores apontados especialmente no artigo $2^{07}$ e, em seguida, suas diretrizes, no artigo $3{ }^{\circ}{ }^{8}$ que, juntos, trazem o direcionamento geral a ser seguido em todo o restante dos planos de proteção, repressão e punição previstos no corpo legal.

Em relação à construção legislativa, cumpre, por ora, dar atenção a esses fundamentos de prevenção, repressão, proteção e demais alterações legislativas contidas nos textos, que vão do artigo 4으 ao artigo 6ㅇ da Lei n. 13.344/2016.

O primeiro artigo a ser analisado é o 4으, que retrata os meios de prevenção a serem aplicados, quais sejam ipsis litteris:

Art. 4ํ. A prevenção ao tráfico de pessoas dar-se-á por meio: I - da implementação de medidas intersetoriais e integradas nas áreas de saúde, educação, trabalho, segurança pública, justiça, turismo, assistência social, desenvolvimento rural, esportes, comunicação, cultura e direitos humanos; II - de campanhas socioeducativas e de conscientização, considerando as diferentes realidades e linguagens; III - de incentivo à mobilização e à participação da sociedade civil; e IV - de incentivo a projetos de prevenção ao tráfico de pessoas.

\footnotetext{
Art. 20 O enfrentamento ao tráfico de pessoas atenderá aos seguintes princípios: I - respeito à dignidade da pessoa humana; II - promoção e garantia da cidadania e dos direitos humanos; III - universalidade, indivisibilidade e interdependência; IV não discriminação por motivo de gênero, orientação sexual, origem étnica ou social, procedência, nacionalidade, atuação profissional, raça, religião, faixa etária, situação migratória ou outro status; $V$ - transversalidade das dimensões de gênero, orientação sexual, origem étnica ou social, procedência, raça e faixa etária nas políticas públicas; VI - atenção integral às vítimas diretas e indiretas, independentemente de nacionalidade e de colaboração em investigações ou processos judiciais; VII - proteção integral da criança e do adolescente.

8 Art. 3o 0 enfrentamento ao tráfico de pessoas atenderá às seguintes diretrizes: I - fortalecimento do pacto federativo, por meio da atuação conjunta e articulada das esferas de governo no âmbito das respectivas competências; II - articulação com organizações governamentais e não governamentais nacionais e estrangeiras; III - incentivo à participação da sociedade em instâncias de controle social e das entidades de classe ou profissionais na discussão das políticas sobre tráfico de pessoas; IV - estruturação da rede de enfrentamento ao tráfico de pessoas, envolvendo todas as esferas de governo e organizações da sociedade civil; $V$ - fortalecimento da atuação em áreas ou regiões de maior incidência do delito, como as de fronteira, portos, aeroportos, rodovias e estações rodoviárias e ferroviárias; VI - estímulo à cooperação internacional; VII - incentivo à realização de estudos e pesquisas e ao seu compartilhamento; VIII - preservação do sigilo dos procedimentos administrativos e judiciais, nos termos da lei; IX - gestão integrada para coordenação da política e dos planos nacionais de enfrentamento ao tráfico de pessoas.
} 


\section{Humanos e}

Democracia

Dessa forma, subtende-se que a prevenção do crime tenta se desenvolver mediante uma perspectiva multifacetada e multidisciplinar, o que denota que alcançar o objetivo de proteger as futuras vítimas e evitar o crime é tão importante que a lei busca trazer um aparato completo dentro das armas que o Estado e a sociedade possam ter. Ele é, de uma forma geral, a explicitação da "necessidade de integração e colaboração mútua" (CUNHA; PINTO, 2016, p. 47).

Nesse sentido, seus dois incisos repercutem em outros dois dispositivos dentro da própria legislação; o primeiro diretamente ao artigo 15 e o segundo ao artigo 3으, inciso II. O primeiro, especificamente, tem a temática intrinsecamente ligada ao fator divulgação, uma clara correspondência e ligação ao trabalho já adiantado pelo II Plano Nacional de Enfrentamento por intermédio dos eventos Campanha Nacional de Conscientização e Sensibilização para Erradicação do Trabalho Escravo e a Campanha Nacional de Prevenção ao Tráfico de Pessoas (BRASIL, 2013a, p. 30).

Trabalhos e previsões como essa explicitam o que já vem abordado no Protocolo de Palermo, que, nos ensinamentos de Francischetto (2013, p. 118), é um instrumento internacional que visa, sobretudo à ampliação da proteção das vítimas de tráfico de pessoas.

Não obstante a necessidade da divulgação, o artigo 40 reitera uma das necessidades apontadas no inciso II do 3으, qual seja, a articulação imprescindível entre órgãos estatais e entre as camadas mais diversas da sociedade civil. Esse trabalho em conjunto também foi retratado e previsto no supracitado Plano Nacional (BRASIL, 2013a, p. 19), sempre com o fito de fortalecer a cadeia de enfrentamento ao tráfico de pessoas.

Seguindo a construção da lei e voltando-se a atenção ao artigo 50, temos a estruturação dos meios de repressão ao tráfico, que se coloca diante de três incisos, a saber:

I - da cooperação entre órgãos do sistema de justiça e segurança, nacionais e estrangeiros; II - da integração de políticas e ações de repressão aos crimes correlatos e da responsabilização dos seus autores; III - da formação de equipes conjuntas de investigação.

A necessidade desse dispositivo destrinchando as formas de repressão é, por si só, autoexplicativa em virtude da própria construção do direito penal que é, em sua natureza, repressor na medida em que objetiva proteger os bens jurídicos. ${ }^{9} \mathrm{Um}$ dos seus principais objetivos é o controle social e a punição efetiva dos que entrarem no tipo e violarem bens jurídicos protegidos (BITENCOURT, 2012, p. 97).

Ressalte-se que os incisos I e II do referido artigo são uma recolocação do disposto no artigo 4을 inciso I, de uma forma a observar as mesmas ferramentas no sentido de garantir da aplicação da norma legal e punição do algoz. Não obstante, seu último inciso chama atenção ao fato de resguardar diretamente o que traz o Protocolo adicional à Convenção da ONU sobre o Crime Organizado Transnacional Relativo à Prevenção, Repressão e Punição do

\footnotetext{
Conforme Cezar Roberto Bitencourt, "a proteção de bem jurídico, como fundamento de um Direito Penal liberal, oferece, portanto, um critério material extremamente importante e seguro na construção dos tipos penais" (2012, p. 76), o que sintetiza a importância de uma legislação bem formulada para a garantia da efetiva proteção desses direitos.
} 
Tráfico de Pessoas, em Especial Mulheres e Crianças, ${ }^{10}$ no seu artigo 10, ponto 2,11 que busca aumentar e fomentar o intercâmbio de informações e formação para maior efetividade das atividades realizadas.

Encerrando a construção em cima do Triplo "P" já apontado, o artigo 60 objetiva delimitar e encarar exaustivamente as formas de proteção e assistência às vítimas, sejam elas diretas ou indiretas. Assim observa-se no texto legal:

Art. 60 A proteção e o atendimento à vítima direta ou indireta do tráfico de pessoas compreendem: I - assistência jurídica, social, de trabalho e emprego e de saúde; II - acolhimento e abrigo provisório; III - atenção às suas necessidades específicas, especialmente em relação a questões de gênero, orientação sexual, origem étnica ou social, procedência, nacionalidade, raça, religião, faixa etária, situaçã̃o migratória, atuação profissional, diversidade cultural, linguagem, laços sociais e familiares ou outro status; IV - preservação da intimidade e da identidade; $V$ - prevenção à revitimização no atendimento e nos procedimentos investigatórios e judiciais; $\mathrm{VI}$ - atendimento humanizado; $\mathrm{VII}$ - informação sobre procedimentos administrativos e judiciais. § 1ㅇ A atenção às vítimas dar-se-á com a interrupção da situação de exploração ou violência, a sua reinserção social, a garantia de facilitação do acesso à educação, à cultura, à formação profissional e ao trabalho e, no caso de crianças e adolescentes, a busca de sua reinserção familiar e comunitária. § 20 № exterior, a assistência imediata a vítimas brasileiras estará a cargo da rede consular brasileira e será prestada independentemente de sua situação migratória, ocupação ou outro status. § 3 o A assistência à saúde prevista no inciso I deste artigo deve compreender os aspectos de recuperação física e psicológica da vítima.

De tal feita, a proteção é elemento primordial dentro do enfrentamento ao crime de tráfico de pessoas, uma vez que, sem ela, pessoas viram objetos para simples obtenção de lucro. Tal proteção é fundamental em razão de diversas vulnerabilidades sociais existentes, quando se observa questões de todo o meio social da vítima (BORGES, 2013, p. 15).

Não à toa, o artigo 60 é o maior, em extensão, dos três pilares de enfrentamento aqui explicitados. Afinal, é ele que se desenvolve abordando questões relevantes e com sensibilidade social em relação às vítimas.

A subdivisão das suas formas de proteção pode ser apontada em duas: aquelas que se relacionam ao processo de evitar a revitimização social e institucional, presentes, nesse caso, nos incisos III, IV, V, VI e VII, e aquelas que objetivam promover a proteção assistencial das vítimas, as quais são explicitadas neste artigo em seus incisos I, Il e seus parágrafos.

Nesse sentido, na linha apontada na primeira subdivisão, os incisos III e IV trazem em seu corpo uma atenção específica em relação às revitimizações sociais provocadas pelos estigmas associados pelo envolvimento em tráfico, quando a vítima perde não somente a liberdade de ir e vir, mas a de domínio sobre seu próprio corpo e, posteriormente, vulnerabiliza-se

\footnotetext{
${ }^{10}$ Convenção que originou o já nomeado Protocolo de Palermo.

${ }^{11}$ É definido pelo artigo 10 em seu ponto 2 que: "Os Estados Partes assegurarão ou reforçarão a formação dos agentes dos serviços competentes para a aplicação da lei, dos serviços de imigração ou de outros serviços competentes na prevenção do tráfico de pessoas. A formação deve incidir sobre os métodos utilizados na prevenção do referido tráfico, na ação penal contra os traficantes e na proteção das vítimas, inclusive protegendo-as dos traficantes. A formação deverá também ter em conta a necessidade de considerar os direitos humanos e os problemas específicos das mulheres e das crianças bem como encorajar a cooperação com organizações não-governamentais, outras organizações relevantes e outros elementos da sociedade civil" (ONU, 2000).
} 


\section{Humanos}

Democracia

no retorno ao meio social e também sobre a necessidade de intimidade pos factum em razão de desconforto por serem vítimas. Conforme Silva (2013, p. 427), "o traficante se aproveita da situação de vulnerabilidade da pessoa, já que a mesma se encontra em lugar alheio e estranho a seu entorno social", e tal vulnerabilidade redobra-se no retorno ao convívio em sociedade, especialmente se essa exploração foi de cunho sexual, sendo essa a preocupação central deste inciso.

Além disso, atenta-se à questão de gênero, que, como apontada anteriormente, é um fato batido mais intensamente dentro do tráfico de pessoas, principalmente no que concerne especificamente ao Brasil. Sabe-se, pelo Relatório Nacional sobre Tráfico de Pessoas de 2013, que $66 \%$ dos casos foram de tráfico para exploração sexual e, dentre estes, 36 dos 41 casos envolveram vítimas do sexo feminino.

Já com relação aos incisos V, VI e VII, o foco de sua construção pauta-se sobre a proteção dentro das instituições que previnem, investigam os casos e acolhem as vítimas, uma vez que, segundo Flaviane de Magalhães Barros (2008, p. 53), a revitimização institucional consiste "não no sofrimento sentido pela vítima [...], mas no desrespeito aos direitos e garantias fundamentais dentro e fora do processo penal". Dessa forma, a adoção de um dispositivo que se preocupa com a recepção desses vulneráveis denota uma atenção humana e social ativa na busca de lhes informar e garantir seus direitos plenamente.

No que concerne aos incisos I e II, seus textos são diretamente ligados à pretensão assistencial pós-crime, no sentido de trazer a vítima ao meio social de forma efetiva e com segurança suficiente para isso. Ambos bebem da fonte do Protocolo de Palermo em seu artigo 6으, bem como da estipulação do II PNETP na meta 2.D.6. da linha operativa $1,{ }^{12}$ que almeja o pleno apoio institucional para uma assistência social às vítimas com efetiva qualidade.

Já em relação a seus três parágrafos, eles, em conjunto, reúnem em suas estruturas a necessidade expressa de assistência familiar, educacional, profissional, de saúde e de reinserção social comunitária, visto ser o crime de tráfico um desenraizador por excelência. $\mathrm{O}$ foco do parágrafo primeiro pauta-se exatamente nisso, enquanto o parágrafo terceiro objetiva sinalizar a necessidade de cuidado com a saúde da vítima, não somente física, mas, também, psicológica.

\footnotetext{
${ }^{12}$ Atividade 2.D. Criar, financiar e realizar estratégias de integração dos sistemas nacionais para atendimento e reintegração das vítimas do tráfico de pessoas, fortalecendo a rede de atendimento, integrando normativas e procedimentos, articulando as responsabilidades entre atores da rede, definindo metodologias e fluxos de atendimento, e disseminando material informativo para um adequado processo de atendimento sob a perspectiva de direitos. Meta 2.D.6 - Serviços de acolhimento institucional assegurados pela política de assistência social para pessoas vítimas de tráfico, criados e fortalecidos, em parceria com setores governamentais e não governamentais.
} 
Por fim, seu parágrafo segundo abrange a proteção das vítimas brasileiras no exterior, e determina, para isso, a existência de consulados que atenderão essas pessoas independentemente da sua situação migratória, ${ }^{13}$ Demonstrando, mais uma vez, que o respeito à dignidade humana e aos direitos humanos deve sempre prevalecer ${ }^{14}$ em detrimento de situações legais diversas, como uma migração realizada de forma inadequada para fins de tráfico.

\section{ANÁLISE CRÍTICA SOBRE A PROTEÇÃO DOS DIREITOS HUMANOS FUNDAMENTAIS E A LEI N. 13.344/16}

Para se compreender a construção jurídica da proteção, é importante entender a relevante posição do indivíduo e seus direitos inerentes. Conforme expõe Comparato (2015, p. 34), "a humanidade como espécie, e cada ser humano em sua individualidade, é propriamente insubstituível: não tem equivalente, não pode ser trocado por coisa alguma".

Daí decorre a ideia de que não se pode deixar ao léu postulados que preservem essa identidade humana como digna e dotada de liberdade. A preservação de tal conceito se consubstancia dentro da própria proteção dos direitos humanos fundamentais de um ser humano. ${ }^{15}$

Ingo Wolfgang Sarlet (2012, p. 102) afirma que "sem que se reconheçam à pessoa humana os direitos fundamentais que lhe são inerentes, em verdade estar-se-á negando-lhe a própria dignidade". Logo, é preciso compreender que proteger os direitos humanos é proteger a dignidade humana e, assim, automaticamente proteger seus direitos fundamentais para se viver de forma plena. ${ }^{16}$

Em relação à tal guarita, as legislações internacional e nacional escritas tornam-se garantidoras institucionalizadas para uma proteção mais maciça dos direitos humanos e, consequentemente, da dignidade da pessoa humana. Nesse sentido, afirma Fábio Konder Comparato $(2015$, p. 73$)$ :

Se a ordem jurídica forma um sistema dinâmico, isto é, um conjunto solidário de elementos criados para determinada finalidade e adaptável às mutações do meio onde atua, os direitos humanos constituem o mais importante subsistema desse conjunto.

Nesse seguimento, não obstante a ordem jurídica internacional de proteção dos direitos humanos subsista por meio de seus instrumentos essenciais (em especial o já citado Protocolo de Palermo e a Declaração Universal dos Direitos Humanos de 1948), as constituições de-

\footnotetext{
${ }^{13}$ Tal previsão dá o alcance necessário trazido no II PNETP na sua meta 2.D.9 que almeja "Consulados brasileiros no exterior instruídos com relação atualizada de casas abrigo para o atendimento emergencial de vítimas brasileiras de tráfico de pessoas".

${ }^{14}$ Para Ingo Wolfgang Sarlet, em seu livro "Dignidade da pessoa humana e direitos fundamentais na Constituição Federal de $1988^{\prime \prime}$, os direitos fundamentais são inerentes à pessoa humana e lhe resguardam a própria dignidade quando devidamente protegidos, mas que está além do ordenamento justamente por ser intrínseca a qualidade de ser humano (2012, p. 84, 102).

15 Para Fábio Konder Comparato, o ser humano vem dotado de um caráter e valores únicos, os quais demonstram que a dignidade da pessoa existe em cada um de forma singular e insubstituível (2015, p. 43).

${ }^{16}$ Cumpre ressaltar que, para Sarlet (2012, p. 102), direitos fundamentais dissociam de direitos humanos, uma vez que direitos humanos são ligados à dignidade humana e os fundamentais são aqueles expressos em texto constitucional, temática aqui não explorada em virtude de o direito fundamental à liberdade violado no tráfico de pessoas ser um direito humano pleno e defendido em diversos tratados e na própria Declaração Universal de 1948, além de contar com expressa proteção na Carta Constitucional de 1988
} 


\section{Humanos e}

Democracia

vem ser alvo de delimitação desses direitos, pois são elas que coadunam os interesses de um povo dentro de uma perspectiva democrática sólida, repousada sobre a dignidade da pessoa humana, em que cada pessoa é um fundamento da sociedade e do próprio Estado (SARLET, 2012, p. 91).

Como grande exemplo de Constituição que abrange esses direitos está a Carta Magna de 1988, à medida que ela trouxe, em seu texto, especialmente dentro do campo de direitos e garantias fundamentais, um dos maiores avanços no que concerne à matéria (PIOVESAN, $2011,207)$. Nessa perspectiva, observa-se, em seu texto, a primazia pela dignidade e direitos em seus artigos 10 a 5으, e em especial ao 4으, inciso II, que traz explicitamente a prevalência dos direitos humanos como um de seus princípios fundamentais. ${ }^{17}$

Dentro do universo da dignidade e dos direitos da pessoa humana está a liberdade individual. Conforme Flávia Piovesan (2011, p. 202), "revela-se esvaziado o direito à liberdade quando não assegurado o direito à igualdade, e por sua vez, esvaziado revela-se o direito à igualdade quando não assegurada a liberdade". Dessa forma, garantir uma proteção e acolhimento a quem tem uma liberdade violada, cerceada injustificadamente, é uma maneira de Ihe garantir a igualdade entre os demais cidadãos. ${ }^{18}$

Uma proteção às vítimas de tráfico de pessoas, portanto. supera uma questão penal e passa a ser responsabilidade do Estado por direitos humanos plenos, em âmbitos nacional e internacional. É preciso, dessa forma, entender que o reconhecimento desses direitos, como o da liberdade individual, não é somente a segurança para a sociedade; é uma forma de institucionalizar valores éticos dentro da coletividade para um pensamento solidário de acolhimento das vítimas (COMPARATO, 2015, p. 71).

A entrada do Protocolo de Palermo dentro do ordenamento brasileiro, seguidos dos I e II PNETP e atual Lei № 13.344 de 2016 representam, justamente, uma perfeita sincronia com uma de nossas cláusulas pétreas presente no artigo 60, §4ํㅡ, inciso IV, da Constituição Federal. ${ }^{19}$

Na opinião de Boaventura de Sousa Santos (1997, p. 9), “[...] o importante é não reduzir o realismo ao que existe, pois, de outro modo, podemos ficar obrigados a justificar o que existe, por mais injusto ou opressivo que seja". Dessa forma, a evolução da proteção das vítimas significa uma quebra de paradigmas em um fato criminoso tantas vezes deixado de lado pela sociedade. Cunha e Pinto (2016, p. 21) destacam, em consonância com tal posicionamento, que "a proteção das vítimas de tráfico de pessoas nada mais é, em última análise, do que a proteção do ser humano, figura central e principal objeto de preocupação do legislador".

Verdade seja, os artigos 2o e 3o da Lei n. 13.344 de 2016 são os responsáveis pela explanação primária dos princípios e diretrizes gerais que rodeiam o enfrentamento ao tráfico de pessoas. Não por acaso, são os dois artigos que formam o primeiro capítulo e a baseiam. São

\footnotetext{
${ }^{17}$ Art. 40 A República Federativa do Brasil rege-se nas suas relações internacionais pelos seguintes princípios: (...) I prevalência dos direitos humanos...

${ }_{18}$ Posicionamento esse dado pela própria Declaração de Direitos Humanos de 1948, que aponta uma concepção indivisível entre o valor da liberdade e da igualdade, os quais devem estar conjugados.

${ }^{19}$ Art. 60 (...) § 40 Não será objeto de deliberação a proposta de emenda tendente a abolir: (...) IV - os direitos e garantias individuais.
} 
neles que se fazem possíveis interpretações voltadas para a garantia da realização existencial do homem. $O$ exemplo disso encontra-se no inciso II do artigo 2:: a prevalência da universalidade que não obsta seus efeitos quanto à busca de maior efetivação na proteção e prevenção contra o delito, contando com diversas forças estatais.

Cunha e Pinto (2016, p. 24) afirmam que "a preocupação do legislador [foi] exatamente [...] promover e garantir a observância dos direitos humanos e da cidadania". Tal afirmativa consubstancia-se na prática ao se fazer a leitura dos dois supracitados artigos, bem como com toda a estrutura trazida pela novel legislação, a qual se mostra como um efetivo aperfeiçoamento e comprometimento do Brasil no reforço do sistema internacional de proteção aos Direitos Humanos.

Ensina Boaventura de Sousa Santos (2010, p. 447) que

A luta pelos direitos humanos e, em geral, pelo exercício da dignidade humana não é um mero exercício intelectual, é uma prática que resulta de uma entrega moral, afectiva (sic) e emocional ancorada na incondicionalidade do inconformismo e da exigência de acção (sic).

Logo, a novel legislação é parte desse modo de reconhecimento da dignidade humana, na medida em que dialoga com o defendido no direito internacional, bem como com as importantes previsões constitucionais de consideração a respeito da dignidade humana plena, além de representar finalmente um posicionamento firme do Brasil no enfrentamento ao tráfico.

\section{CONSIDERAÇÕES FINAIS}

A ideia de se trabalhar com uma nova lei é muito mais do que apenas destrinchar seus conteúdos e replicá-los num texto descritivo, mas avaliar o respeito aos princípios que a fundamentam; principalmente se tal norma compõe-se numa inovação crucial dentro do ordenamento jurídico brasileiro que preza pelo cuidado e proteção de direitos fundamentais de seus cidadãos.

A necessidade de sua criação foi patente e urgente, assim como será a de sua aplicação no decorrer dos anos que se seguirem, devendo serem analisados e acompanhados seus resultados. Nesse sentido, sua criação foi mais um passo para a efetivação da atuação estatal num crime tão precariamente evitado, descoberto e punido.

Destarte, observa-se sua necessidade por meio de diversas previsões legislativas de cunho internacional, que protegiam, no conceito geral, algo que deveria ser observado dentro do Estado soberano brasileiro. Suas evoluções legislativas, ao longo dos anos, especificamente no que concerne ao Código Penal e suas alterações em relação ao tráfico - sendo inicialmente de mulheres, para pessoas, mas vinculado à exploração sexual, para somente então ser um crime contra a liberdade individual -, permitiram alcançar o ideal trazido no Protocolo de Palermo, instrumento internacional de proteção específica em casos de tráfico de pessoas, que, ratificado, finalmente, em 2004, teve seu auge de representação consubstanciado com a referida lei no ano de 2016. 


\section{Humanos e}

Democracia

Depreende-se também da estrutura da lei que seus conceitos não a fazem uma lei crua e engessada; pelo contrário, possui princípios a serem interpretados e aplicados sem the vincular a tempo e, sim, a toda a problemática que se desenvolve; tudo isso com o fito de garantir a efetivação do triplo "P", e, em especial, os "ps" de proteção e prevenção, trazendo atuações mais que necessárias para evitar o crime e proteger as vítimas vulnerabilizadas após sua ocorrência. Não se pode esquecer, claro, da repressão, que, com base no princípio da universalidade trazido na própria norma, busca alcançar a unidade de atuações entre diversos órgãos estatais para maior efetivação da norma e proteção dos direitos das vítimas.

Em que pese falar de direitos, a transformação da ideia do Protocolo de Palermo em realidade, mediante a presente norma, significa mais que proteger a liberdade individual do indivíduo; ela renova o olhar sobre os direitos humanos das vítimas de tráfico, que perdem muito mais que o direito de ir vir livremente, coisificando-a. Compreende-se a lei, nesse contexto, como garantidora de uma proteção às vítimas num crime que as transforma em mercadoria e lhes tira a dignidade.

A liberdade humana é direito essencial tanto como direito humano na Declaração Universal dos Direitos Humanos quanto como direito fundamental na própria Constituição Federal de 1988. Sendo assim, ela é parte da dignidade da pessoa humana, característica intrínseca a todo ser humano que deve ser resguardada pelo seu Estado.

Dessa forma, a vigência da Lei no 13.344 de 2016 representa mais que um marco histórico na proteção dos direitos humanos e fundamentais já almejados. Ela representa uma evolução no caminho para o eficaz enfrentamento ao crime de tráfico de pessoas e a garantia plena da dignidade da pessoa humana.

\section{REFERÊNCIAS}

BARROS, Flaviane de Magalhães. A participação da vítima no processo penal. Rio de Janeiro: Lumen Juris, 2008. BRASIL. Constituição da República Federativa do Brasil, promulgada em 5 de outubro de 1988. Brasília, DF: Senado Federal, 1988.

BRASIL. Decreto-Lei no 2.848, de 7 de dezembro de 1940. Código Penal. Brasília DF: Senado Federal, de 7 de dezembro de 1940.

BRASIL. Decreto no 5.016, de 12 de março de 2004. Promulga o Protocolo Adicional à Convenção das Nações Unidas contra o Crime Organizado Transnacional, relativo ao Combate ao Tráfico de Migrantes por Via Terrestre, Marítima e Aérea. Brasília, DF: Senado Federal, 2004a.

BRASIL. Decreto no 5.017, de 12 de março de 2004. Promulga o Protocolo Adicional à Convenção das Nações Unidas contra o Crime Organizado Transnacional Relativo à Prevenção, Repressão e Punição do Tráfico de Pessoas, em Especial Mulheres e Crianças. Brasília, DF: Senado Federal, 2004b.

BRASIL. Decreto no 5.948, de 26 de outubro de 2006. Aprova a Política Nacional de Enfrentamento ao Tráfico de Pessoas e institui Grupo de Trabalho Interministerial com o objetivo de elaborar proposta do Plano Nacional de Enfrentamento ao Tráfico de Pessoas - PNETP. Brasília, DF: Senado Federal, 2006.

BRASIL. Lei no 13.344, de 6 de outubro de 2016. Dispõe sobre prevenção e repressão ao tráfico interno e internacional de pessoas e sobre medidas de atenção às vítimas; altera a Lei no 6.815, de 19 de agosto de 1980, o Decreto-Lei n. 3.689, de 3 de outubro de 1941 (Código de Processo Penal), e o Decreto-Lei n. 2.848, de 7 de dezembro de 1940 (Código Penal); e revoga dispositivos do Decreto-Lei n. 2.848, de 7 de dezembro de 1940 (Código Penal). Brasília, DF: Senado Federal, 2016.

BRASIL. Ministério da Justiça. Secretaria Nacional de Justiça. II Plano nacional de enfrentamento ao tráfico de pessoas. Brasília: SNJ, 2013a.

BRASIL. Ministério da Justiça. Secretaria Nacional de Justiça. Relatório nacional sobre tráfico de pessoas. Brasília: SNJ, 2013b. 
BITENCOURT, Cezar Roberto. Tratado de direito penal: parte geral, v. 1.17. ed. rev., ampl. e atual. de acordo com a Lei n. 12.550, de 2011. São Paulo: Saraiva, 2012.

BORGES, Paulo César Corrêa (org.). Tráfico de pessoas para exploração sexual: prostituição e trabalho sexual escravo. São Paulo: NETPDH; Cultura Acadêmica Editora, 2013.

CASTILHO, Ela Wiecko Volkmer de. Tráfico de pessoas: da convenção de Genebra ao Protocolo de Palermo. 2008. Disponível em: http://pfdc.pgr.mpf.mp.br/atuacao-e-conteudos-de-apoio/publicacoes/trafico-de-pessoas/artigo_trafico_de_pessoas.pdf. Acesso em: 4 nov. 2017.

COMPARATO, Fábio Konder. A afirmação histórica dos direitos humanos. 9. ed. São Paulo: Saraiva, 2015.

CUNHA, Rogério Sanches; PINTO, Ronaldo Batista. Tráfico de pessoas: lei 13.344/2016 comentada por artigos. Salvador: Juspodivm, 2016.

FRANCISCHETTO, Gilsilene Passon Picoretti. A necessidade de maior visibilidade da comunidade LGBT quanto à prevenção e combate ao tráfico de pessoas. In: BORGES, Paulo César Corrêa (org.). Tráfico de pessoas para exploração sexual: prostituição e trabalho sexual escravo. São Paulo: NETPDH; Cultura Acadêmica Editora, 2013. Série Tutela penal dos direitos humanos, n. 3. p. 115-135.

LEAL, Maria Lúcia; LEAL, Maria de Fátima P. (org.). Pesquisa sobre tráfico de mulheres, crianças e adolescentes para fins de exploração sexual comercial - PESTRAF: Relatório Nacional. Brasília, DF: Cecria, 2002.

ONU. Organização das Nações Unidas. Assembleia Geral das Nações unidas. Declaração universal dos direitos humanos. 1948. Disponível em: http://www.onu.org.br/img/2014/09/DUDH.pdf. Acesso em: 4 nov. 2017.

ONU. Organização das Nações Unidas. Vienna Declaration and Programme of Action (A/CONF.157/23), 1993. Disponivel em: http://www.un-documents.net/ac157-23.htm. Acesso em: 4 nov. 2017.

PASTANA, Debora Regina. Tráfico de pessoas e globalização: a necessidade de construção de uma prática contra hegemônica de enfrentamento. In: BORGES, Paulo César Corrêa (org.). Tráfico de pessoas para exploração sexual: prostituição e trabalho sexual escravo. São Paulo: NETPDH; Cultura Acadêmica Editora, 2013. Série Tutela penal dos direitos humanos, n. 3. p. 95-111.

PIOVESAN. Flávia. A proteção internacional dos direitos humanos. In: PIOVESAN, Flávia; GARCIA, Márcia (org.). Proteção internacional dos direitos humanos. São Paulo: Editora Revista dos Tribunais, 2011. (Coleção doutrinas essenciais; v. 6).

POPPER, Karl Raymund. 1902. Lógica das ciências sociais. Tradução Estevão de Rezende Martins, Apio Cláudio Munis Acquarone Filho e Vilma de Oliveira Moraes e Silva. 3. ed., Rio de Janeiro: Tempo Brasileiro, 2004.

SANTOS, Boaventura de Sousa. Uma concepção multicultural de direitos humanos. Lua Nova, São Paulo, n. 39, p. 105-124, 1997. Disponível em: http://www.scielo.br/scielo.php?script=sci_arttext\&pid=S0102-4451997000100007\&lng=pt\&nrm=iso. Acesso em: 12 jul. 2017.

SANTOS, Boaventura de Sousa. Para uma concepção multicultural dos direitos humanos. In: SANTOS, Boaventura de Sousa. A gramática do tempo: para uma nova cultura política. 3. ed. São Paulo: Cortez, 2010. p. 433-470. (Coleção para um novo senso comum; v. 4).

SANTOS, Boaventura de Sousa; GOMES, Conceição; DUARTE, Madalena; BAGANHA, Maria Ioannis. Tráfico de mulheres em Portugal para fins de exploração sexual. Cidade do Porto, Portugal: Clássica - Artes Gráficas, 2008.

SARLET, Ingo Wolfgang. A eficácia dos direitos fundamentais: uma teoria geral dos direitos fundamentais na perspectiva constitucional. 10. ed. rev. atual. e ampl. 3. tir. Porto Alegre: Livraria do Advogado Editora, 2011.

SARLET, Ingo Wolfgang. Dignidade da pessoa humana e direitos fundamentais na Constituição Federal de 1988. 9. ed. rev. atual. 2. tir. Porto Alegre: Livraria do Advogado Editora, 2012.

SILVA, Waldimery Corrêa da. Tráfico de pessoas: necessidade de clareza conceitual entre o tráfico internacional de pessoas e contrabando de pessoas. In: PAGLIARINI, Alexandre Coutinho; RIBEIRO, Márcia Carla Pereira (org.). Sociedade e Direito. Rio de Janeiro: GZ Editora, 2013. p. 417-436.

UNODC. United Nations Office on Drugs and Crime. Global report on trafficking in persons. New York: United Nations, 2016. Disponível em: https://www.unodc.org/documents//po-brazil//Topics_TIP/Publicacoes/2016_Global_Report_on_Trafficking_in_Persons.pdf. Acesso em: 12 jul. 2017.

VENSON, Anamaria Marcon; PEDRO, Joana Maria. Tráfico de pessoas: uma história do conceito. Revista Brasileira de História, São Paulo, v. 33, n. 65, p. 61-83, 2013. 